\title{
CORRESPONDENCE
}

Migraine in childhood

M A Salmon, FRCPED, and others...... 1481

Routine procedures in general

anaesthesia

G C Steel, fFarcs . . . . . . . . . . 1481

Standards for surgical therapeutic

trials

D H Spodick, MD, and others........ 1482

Uniform style for biomedical journals

K G M M Alberti, MRCPATH; R Hole, FRCS 1482

Interrelated factors in hypertensive patients

V M Hawthorne, FRCPGLAS, and Mary

Smalls, BSC; J H Fuller, MRCP, and others.. 1483

The Stomach Cancer Group

P F M Wrigley, MRCP, and V S Brookes,

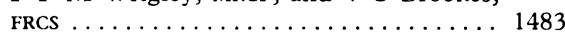

Television medicine

J Apley, FrCP................ 1483

Treatment of tuberculosis

A Seaton, FRCP.............. 1484

Diuretics in the elderly

S Waldek, MRCP; D M Burley, MRCP.... 1484

Sulphinpyrazone after myocardial

infarction

S H Kane, MD . . . . . . . . . . . . 1484

Plasma urate changes in

pre-eclampsia

C W G Redman, MRCP, and J Bonnar,

FRCOG .................... 1484

Rubella vaccination

Leonora A Crawford, MFCM.......... 1485
Coronary heart disease and male sex hormones

Ingrid $\mathrm{L}$ Waldron, PHD

Cetiprin (emepronium bromide) in patients with prostatism

E S Glen, FRCSED; A D Lauder, MB...... 1485

Stricture of oesophagus associated with ankylosing spondylitis

A P Weetman, MB...

Is pancreatic isotope scanning worth while?

P B Cotton, FRCP...

Psychiatric problems after mastectomy

H G Kinnell, MRCPSYCH . . . . . . . . . . . 148

Cimetidine and protective effect of mucus in gastric ulcer

M Guslandi, MD, and others. . . .

Painful young bellies

I H J Bourne, FRCGP; H A Goudarzi, FRCs 1486

"Innovation in the Pharmaceutical

Industry"

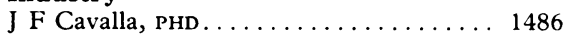

Plasmapheresis

Daisy Obeid, MB, and Paula Cotter, MD . . 1486

Vincristine-induced neuropathy in

lymphomas

Sylvia $M$ Watkins, DM, and J P Griffin,

PHD, MB................... 1487

Geriatric beds

R L G Sutcliffe, FRCPED.

Ultrasound and work load in the radiology department

B M Gompels, FRCR. .
Pituitary tumours and pregnancy

K W Hancock, MRCOG, and others...

Factors influencing the incidence of

neonatal jaundice

B S B Wood, frCP............. 1488

Myelography and lumbar venography

R G Grainger, FRCP, FRCR . . . . . . . . . 1488

Pilots' hearts

J H McKillop, MRCP, and others....... 1488

Surgery for intermittent claudication

C V Ruckley, fRCSED . . . . . . . . . . . . 1489

Umbilical cord prolapse

T Vago, MD . . . . . . . . . . . . . . . . . 1489

Cough mixtures

D Adler, Mrcs . . . . . . . . . . . . . 1489

A British "Doctors' Ten"

R C Goodfellow, мB . . . . . . . . . . . . . . 1489

Shortage specialties

J L C Dall, FRCPGLAS . . . . . . . . . . . . 1489

BMA and the Abortion Act

D C Flint..............

New consultant contract

P W Fisher, FRCP; G Johns, FFARCS; A E

Carter, frCs . . . . . . . . . . . . 1490

Setting an example

J S Elkington, FRCS, and Gillian Elkington 1491

Economy in drug prescribing

J D Williamson, MRCGP; D Sapsford, MB . . 1491

Future of British anaesthetics

$M$ D A Vickers, fFARCS, and $M$ Rosen,

1491

Abuse of Form Med 3

$\mathrm{J} M$ Anderson, $M B$

Pay of vocational trainees

M H Owen, MB.................. 1491
Correspondents are urged to write briefly so that readers may be offered as wide a selection of letters as possible. So many are being received that the omission of some is inevitable. Letters must be signed personally by all their authors.

\section{Migraine in childhood}

SIR,-The frequency of childhood migraine is poorly appreciated in many paediatric textbooks, so we the undersigned, who are concerned at the lack of understanding of migraine in children, have been discussing the topic at two meetings organised by the British Migraine Association. We would like to draw the attention of our colleagues to our conclusions and open the subject to discussion.

In 1962 the Ad Hoc Committee on Classification of Headache ${ }^{1}$ defined migraine as "Recurrent attacks of headache, widely varied in intensity, frequency and duration. The attacks are commonly unilateral in onset; are usually associated with anorexia and, sometimes, with nausea and vomiting; in some are preceded by, or associated with, conspicuous sensory, motor and mood disturbances; and are often familial." This definition is widely accepted. It is, however, founded on presentations of migraine in adults, and does not cover certain aspects of the condition as it presents in children.

We found migraine in childhood difficult to define. It may present from early infancy on, and under the age of 10 has an equal sex incidence. All known types occur, classical and common migraine being the most frequent presentations. Migraine of so-called basilar, hemiplegic, and ophthalmoplegic type can also be recognised from infancy onwards.

Typically, migraine attacks in childhood have an acute onset with headache, commonly frontal, accompanied by some of the following features: nausea with or without vomiting, anorexia, malaise, pallor, and a desire to sleep. Less commonly there may be eye pain, profound lethargy with or without hypotonia, sensory (commonly visual), motor, or mood disturbance, ketosis, and pyrexia. Attacks are usually over within $24 \mathrm{~h}$, but episodes may cluster. In some children headache may be insignificant and the systemic upset predominant; such cases are not always readily diagnosed or accepted as migraine.

There are various symptom complexes which may be associated with migraine in childhood, although the validity of the relationship is not clearly established. These include: (a) Recurrent abdominal pain-colicky or epigastric aching; the pain is short-lived and central and may be accompanied by abdominal distension, nausea, and vomiting; the vomiting may be biliary, and lead to ketosis and de- hydration (cyclical vomiting). (b) Episodic malaise, with anorexia, pallor, fever, and pale stools.

Our studies of this subject are continuing and we would appreciate observations.

\begin{tabular}{|c|c|}
\hline Michael Salmon & P GUZDER \\
\hline KaTHARINA DALTON & E WATERS \\
\hline MARGARET SWEENEY & Michael DaltoN \\
\hline JUDITH HOCKaDAY & BARRY LEWIS \\
\hline JOHN WILSON & D HOOPER \\
\hline $\begin{array}{r}\text { W FORSYTHE } \\
\text { K HAY }\end{array}$ & MAUREen DaLton \\
\hline
\end{tabular}

${ }^{1}$ Friedman, A P, et al, Archives of Neurology, 1962, 6, 73.

\section{Routine procedures in general} anaesthesia

SIR,-I am grateful to those who have commented on my Personal View (22 April, $p$ 1049) both through your columns and in personal letters: in the latter case I am particularly grateful for the kind comments that have been made.

Dr M A Thompson's pleasantly temperate letter (13 May, p 1275) suggests that my communication illustrates the changes between anaesthesia as it used to be and as it is now, which may well be the case. This change, if I interpret his letter correctly, is exemplified by the increased use of relaxants and of the endotracheal tube in cases in which the latter is not necessarily essential to the maintenance of a good airway. Up to the time of my 
retirement I had never read-and I doubt if Dr Thompson had either-of the incidence among anaesthetists of an unpleasantly dry throat or of muscular discomfort on the day after they have given relaxants and passed routine endotracheal tubes on patients. But both he (I assume) and I are aware of the patients' liability to experience these discomforts in the postoperative period. That is unless, of course, anaesthesia of today has magically transferred these discomforts to the concerned anaesthetists as a form of updated couvade. One of my personal correspondents wrote: "I must confess that in the last few months before my retirement, I used to use an endotracheal tube to save myself the chore of holding up the chin." Do those practising $\mathrm{Dr}$ Thompson's anaesthesia of today believe that it is ethically within the remit of the anaesthetist, whose first obligation is, or used to be, to the welfare of the patient, to pass the unnecessary tube which may add, albeit possibly only to a minor degree, to the patient's postoperative discomfort? This for reasons which I have suggested or, less commendably, to avoid a physical chore? I suggest that the practitioner of anaesthesia as it is today, poised ready to pass the unnecessary tube, should ask himself the question posed by Marcus Tullius Cicero: "Cui bono?"

I am also unhappy about Dr Thompson's fiat that an endotracheal tube is "mandatory" for a caesarean section. "Desirable," yes. "Highly desirable," yes. But "mandatory" is too absolute; it brooks of no elasticity or compromise. In the minds of juniors with an implicit faith in the authority of the written word it can have a dangerous effect, this being that he is indoctrinated to believe that it is virtually impossible for the operation to be done unless the tube has been successfully passed. Intubation of a possibly already fat woman at term can present considerable anatomical difficulties, and in such circumstances he may feel impelled to persist in his efforts at a difficult intubation for an unduly long time with the risk of the patient/or fetus, or both, becoming suboxygenated. It is not unknown for maternal death to be the final outcome of a prolonged duel of this nature. Here I assure Dr Thompson that I am not merely indulging in theoretical speculation or "flying a kite" (pace Dr P V Scott (13 May, p 1275)). Dr M E Tunstall has produced a film of outstanding excellence showing the drill to be undertaken in the event of the difficulties of intubation being insurmountable. If there is any procedure that may be termed mandatory I suggest that it is the showing of this film to al successive groups of junior anaesthetists who may be concerned with obstetric anaesthesia.

Additionally, Dr Thompson queries the wisdom of the priorities with which I dealt with the emergency that $I$ have described: and we know that the finest rugger is invariably played by the spectators in the stands. But I still believe my priorities were right. I was confronted with worried surgeon, a demoralised anaesthetist, and a cyanotic patient with a tube in situ, the latter clearly being responsible for the cyanosis. If by chance the trouble had been due to a manufacturing fault in the tube with an imperfect lumen the result of wasting time in adjusting the position of a faulty tube would only have worsened the situation. Surely the golden rule is a respected paraphraseology of Holy Writ-"If thy tube offend thee, pluck it out and cast it from thee."

Dr Scott reproaches me for not defining the dangers of administration of oxygen and has evidently failed to take up the reference which gave to the letter from Professor Macintosh which dealt with the subject. He also kindly provides us with a list of references in support of his contentions but has omitted to mention other episode relating to postoperative hypoxia and to the clinical use of oxygen. He refrains from reminding us of the bizarre promulgation of the causation of postoperative hypoxia by the preoperative use of atropine; nor is any mention made of the dangerous and futile idiocy of the administration of intragastric oxygen for neonatal respiratory depression; and a discreet silence is also maintained over the unphysiological and useless practice of hyperbaric oxygen for that same condition. The gullibility with which these follies were initially accepted until eventually they were deservedly discredited and cast into the dustbin of disrepute makes those of us who can recall them have some slight reservations about the all too frequent occurrence of scientifically proved new discoveries. Certainly these events remain fresh in my memory even if they have been conveniently expunged from that of Dr Scott; and regrettably the stridency of his apologia for them does little to dispel these reservations.

Of Dr Scott's final paragraph all that is conveyed to me is the impression of a not very healthy preoccupation with the law and its subsidiary functions. We are harangued about kite-flying, the role of a prosecuting counsel, then progress to the court of law and "avoidable factors" up to the climax of the coroner-cold and unsympathetic to boot. That the promulgator of such an addled farrago should chide anyone else for the use of extravagant phraseology is surely the classic instance of the Devil rebuking Sin. My personal experience of coroners and their ways has been so meagre that I am not fitted to debate with Dr Scott on this subject and therefore bow to his authority. If, however, any of his coroners consider themselves to have been given cause to behave coldly and unsympathetically I would like to try to redress the balance by conveying to him my most warm and unstinted sympathy over any such unhappy incidents.

G C STEEL

Roehampton

\section{Standards for surgical therapeutic trials}

SIR,-In theory, reviewers of scientific papers impose standards for acceptance based on the aim of all scientists - to report a true result For therapeutic trials a true result depends on appropriate design-that is, the results should reveal real treatment effects by measures which minimise biases in selecting patients and administering therapy. Acceptance of the results for publication implies merit, and without publication it is very difficult to establish a new treatment in practice. Medical journals thus become the filter through which appropriately studied modalities can go on to application but through which inappropriately studied modalities should not be able to pass. While this has been increasingly true for medicinal agents, it has not been the case for new surgical procedures and new applications of established procedures. Most journal reviewers, abstract referees for scientific meetings, and hospital research committees maintain high standards for the design of medical therapeutic trials. Yet they do no impose equal standards for surgical trials. This is not because such trials cannot be done

It has been shown that prospective con trolled trials of surgical therapy, including random allocation of patients, are quite feasible though perhaps more complicated to perform than comparably designed trials of non-surgical therapy. Relatively few, however have been done, and these have followed rather than preceded the widespread introduction of new operations. Yet to establish as early as possible (a) that a treatment is truly effective and (b) exactly for whom it is indicated the same principles must apply to all therapies. Unless this is recognised uncertainty will continue to provoke controversies like the protracted arguments over appropriate operations for common diseases like peptic ulcer, breast carcinoma, and coronary artery obstruction. The years consumed and the heat generated by disputants whose skill and intellect are undoubted testify to the persistent problem of getting valid evidence-to the detriment of our patients. We believe that this is the result of the absence of appropriate standards of proof for new surgical treatments and new applications of existing surgical treatments.

There is no scientific or humanistic reason why standards for acceptance should not be equal for all treatments. On the contrary, science and ethics demand our best efforts for equal standards. Moreover, there is every reason for their application from the very first clinical trial of each treatment. It is true that reduction of operative mortality improves with experience, yet proof of current benefit to patients necessarily applies to current experience. Our point is related to the quality of such proof.

We believe that the publication "filter" is the place to maintain equally high standards for all treatments. We request the editors and reviewers of the British Medical Fournal to consider an explicit policy of equal standards for therapeutic trials of all therapies.

\section{David H Spodick}

University of Massachusetts

\begin{tabular}{|c|c|}
\hline WILBERT ARONOW & BERNARD LOWN \\
\hline BERNARD BARBER & VIRENDRA S MATHUR \\
\hline HENRY BLACKBURN & HENRY D MCINTOSH \\
\hline DAVID BOYD & ThOMAS A PRESTON \\
\hline C RichaRd Conti & ARThUR SELZER \\
\hline JAMES P LOGERFO & TIMOTHY TAKARO \\
\hline
\end{tabular}

* *'The criteria applied by the $B M F$ and its referees in assessing the standard of surgical therapeutic trials are precisely the same as those used for medical trials.-ED, BMF.

\section{Uniform style for biomedical journals}

SIR,-I was delighted to see the article from the International Steering Committee of Medical Editors (20 May, p 1334) and the accompanying leading article (p 1302). I write both as an editor and as a submitter of papers. As the latter I spend a great deal of time perusing instructions to authors and pushing references into appropriate shapes. This can be particularly irritating if a paper is rejected by one journal and one wishes to submit it elsewhere. Invariably, changes in style have to be made. The only advantage is that it forces one to think a little bit more about the paper before it is sent out again. As an editor, it can be equally irritating to spend hour after hour correcting errors in format. One gets the impression that $50 \%$ of authors adopt their own idiosyncratic style for presentation of manuscripts and use this uniformly for all journals. The only usefulness that one can see as an editor of differences between journals is that it is sometimes possible to work out which journals have just rejected the paper one is reading.

In general, there can be no argument against uniformity. It would help authors and help editors alike. The argument that it would 